\title{
(1) \\ AVALIAÇÃo dAS UNIDAdES DE TRATAMENTO dO LODO EM \\ UMA ETE DE LODOS ATIVADOS CONVENCIONAL SUBMETIDA A DISTINTAS ESTRATÉGIAS OPERACIONAIS
}

\author{
EVALUATION OF THE SLUDGE TREATMENT UNITS IN AN ACTIVATED SLUDGE \\ TREATMENT PLANT SUBJECTED TO DIFFERENT OPERATIONAL STRATEGIES
}

\section{ALESSANDRA VALADARES ÁLVARES DA SILVA}

Arquiteta urbanista (FAMIH-MG). Especialista em Engenharia Sanitária e Ambiental (UFMG). Mestre em Saneamento, Meio Ambiente e Recursos Hídricos (UFMG)

\section{MARCOS VON SPERLING}

Doutor em Engenharia Ambiental pelo Imperial College, Universidade de Londres. Professor Adjunto do Departamento de Engenharia Sanitária e Ambiental da UFMG

\section{José MARIa DE OlIVEIRA FILHO}

Engenheiro civil pela Universidade Federal de Minas Gerais (UFMG). Especialista em Engenharia Sanitária e Ambiental (UFMG). Gerente da Divisão de Tratamento de Efluentes - COPASA

Recebido: 26/12/06

Aceito: 22/03/07

\section{RESUMO}

A finalidade deste trabalho é apresentar uma avaliação da etapa de tratamento de lodos da Estação de Tratamento de Esgotos do Arrudas (Belo Horizonte), em especial os teores de sólidos ao longo do sistema, as principais variáveis de projeto e operação. O processo de tratamento é o de lodos ativados convencional com adensamento por gravidade, digestão anaeróbia e desidratação mecânica. Desde sua entrada em operação até o momento, a estação passou por três fases operacionais quanto ao adensamento dos lodos. A maior concentração média do lodo primário $(4,8 \%)$ foi atingida no adensador por gravidade quando esse recebia apenas lodo primário. $\mathrm{O}$ lodo misto alcançou uma concentração média de $2,7 \%$ enquanto o valor esperado de projeto era 5,0\%. O lodo secundário excedente, concentrado no adensador por gravidade não ultrapassou 1,8\%. A maior concentração média da torta do lodo desidratado $(28,3 \%)$ foi obtida quando o lodo digerido era proveniente do tratamento primário.

PALAVRAS-CHAVE: Esgoto, tratamento do lodo, adensamento, digestão anaeróbia, desidratação.

\section{ABSTRACT}

This paper aims to evaluate the sludge treatment stage at the Arrudas Wastewater Treatment Plant (Belo Horizonte, Brazil), especially the solids contents throughout the sludge treatment line, as well as the main design and operating variables. The conventional activated sludge plant has a typical solids-line flowsheet: gravity thickening, anaerobic digestion and mechanical dewatering. Three main operational phases have been identified, whose implications in the plant behaviour are analysed in the paper. The highest concentration of primary sludge (mean value of $4.8 \%$ ) was reached in the gravitational thickening when it was fed with primary sludge only. The mixed sludge concentrated in the gravitational thickening reached only a mean concentration of $2.7 \%$, whereas the expected result was $5.0 \%$. The excess secondary sludge concentrated in the gravitational thickener did not reach $1.8 \%$. The largest concentration of the dewatered sludge cake (means value of $28.3 \%$ ) was obtained when the digested sludge came from the primary treatment.

KEYWORDS: Wastewater, sludge treatment, thickening, anaerobic digestion, dewatering.
INTRODUÇÃO
A Estação de tratamento de es- gotos do Arrudas trata os esgotos gerados na Bacia do Arrudas, em Belo Horizonte e Contagem - MG. A ETE localiza-se nas proximidades da divisa dos municípios de Belo Horizonte e Sabará e situa-se à margem esquerda do Ribeirão Arrudas. A Estação entrou em operação em outubro de 2001 com o tratamento primário e em janeiro de
2003 com o tratamento secundário pelo processo de lodos ativados convencional. O tratamento primário foi construído para atender a uma vazão média de fim de plano de $4,50 \mathrm{~m}^{3} / \mathrm{s}$, ao passo que o tratamento secundário foi implantado para uma vazão inicial de $2,25 \mathrm{~m}^{3} / \mathrm{s}$ (aproximadamente 1.000.000 habitan- tes). A ETE é operada pela Companhia de Saneamento de Minas Gerais, COPA- SA. A Figura 1 apresenta o fluxograma do processo de tratamento.
O objetivo do presente trabalho é avaliar o comportamento do lodo ao longo das etapas que compóem a fase sólida de uma estação de lodos ativados de grande porte, e comparar as princi- pais variáveis operacionais das unidades com valores usualmente recomendados para projeto ou operação. No Brasil, as estações de tratamento de esgotos por lodos ativados têm sido dimensionadas com base em normas técnicas ou livros clássicos, e há poucas avaliações do 
real desempenho e dos parâmetros de projeto empregados, principalmente no que diz respeito à etapa de tratamento do lodo.

Desde sua implantação, a Estação passou por três diferentes fases operacionais no que se refere ao adensamento dos lodos. A Tabela 1 apresenta estas fases, as quais tiveram uma profunda implicação em todo o comportamento da fase sólida, conforme apresentado no presente trabalho. Os valores médios da vazão de esgotos afluente à ETE foram: Fase 1: 1,10 $\mathrm{m}^{3} / \mathrm{s}$; Fase 2: $1,21 \mathrm{~m}^{3} / \mathrm{s}$; Fase $3: 1,33 \mathrm{~m}^{3} / \mathrm{s}$. Os dados básicos das unidades que tratam o lodo da ETE Arrudas estão apresentados na Tabela 2.
PARÂMETROS

USUAIS DE PROJETO

E OPERACÃO NO

TRATAMENTO DO LODO

Diversos trabalhos abordam o tratamento do lodo em estações brasileiras e estrangeiras (von Sperling, 1997;

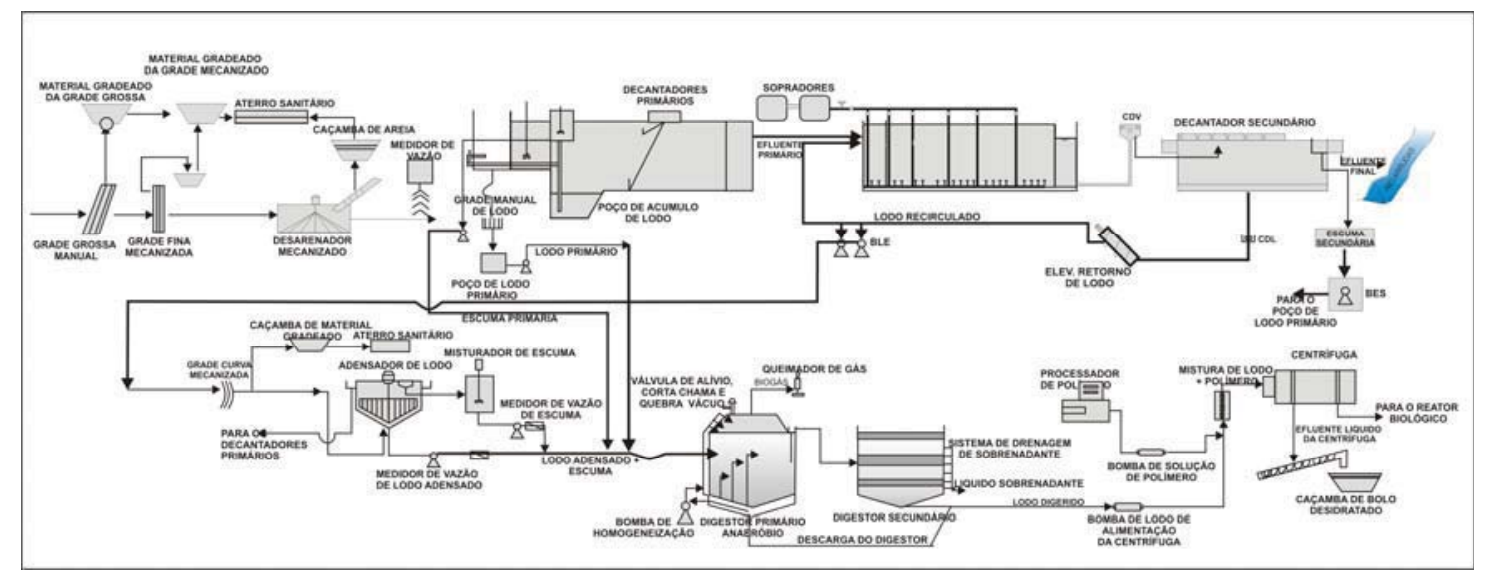

Fonte: Adaptado de SILVA, 2002, v.7, p. 8.

Figura I - Fluxograma da ETE Arrudas

Tabela I - Fases operacionais no tratamento do lodo da ETE Arrudas

\begin{tabular}{|c|c|c|c|c|c|}
\hline Fase & $\begin{array}{l}\text { Nível do } \\
\text { tratamento }\end{array}$ & Período & Adensamento & Digestão & Descrição \\
\hline 1 & $\begin{array}{l}\text { Somente } \\
\text { tratamento } \\
\text { primário }\end{array}$ & $\begin{array}{c}\text { out } / 2001 \text { a } \\
\text { dez/2002 }\end{array}$ & $\begin{array}{l}\text { - LP no } \\
\text { adensador }\end{array}$ & - LP adensado & $\begin{array}{l}\text { - Lodo primário concentrado no adensador por } \\
\text { gravidade e bombeado para o digestor. }\end{array}$ \\
\hline 2 & $\begin{array}{l}\text { Tratamento } \\
\text { secundário }\end{array}$ & $\begin{array}{l}\mathrm{jan} / 2003 \mathrm{a} \\
\mathrm{ago} / 2004\end{array}$ & $\begin{array}{l}\text { - LM no } \\
\text { adensador }\end{array}$ & $\begin{array}{l}\text { - LM } \\
\text { adensado }\end{array}$ & $\begin{array}{l}\text { - Lodo primário e lodo secundário concentrados, } \\
\text { conjuntamente, no adensador por gravidade e } \\
\text { bombeados para o digestor. }\end{array}$ \\
\hline 3 & $\begin{array}{l}\text { Tratamento } \\
\text { secundário }\end{array}$ & $\begin{array}{l}\text { ago/2004 a } \\
\text { jun/2005 }\end{array}$ & $\begin{array}{l}\text { - LP adensado } \\
\text { no dec prim } \\
\text { - LS no } \\
\text { adensador }\end{array}$ & $\begin{array}{l}\text { - LP do dec } \\
\text { prim } \\
\text { - LS adensado }\end{array}$ & $\begin{array}{l}\text { - Lodo primário adensado no próprio decantador primário } \\
\text { e bombeado, diretamente, para os digestores. } \\
\text { - Lodo secundário concentrado no adensador por gravidade } \\
\text { e bombeado para o digestor. }\end{array}$ \\
\hline
\end{tabular}

Tabela 2 - Dados das unidades da fase sólida da ETE Arrudas (vazão média de projeto: 2,5 m³/s)

\begin{tabular}{|c|c|c|c|c|c|}
\hline \multirow[t]{2}{*}{ Dados Técnicos } & \multicolumn{5}{|c|}{ Unidades } \\
\hline & $\begin{array}{c}\text { Decantadores } \\
\text { Primários } \\
\end{array}$ & Adensador & $\begin{array}{l}\text { Digestores } \\
\text { Primários } \\
\end{array}$ & $\begin{array}{l}\text { Digestores } \\
\text { Secundários }\end{array}$ & Desidratação \\
\hline Número de unidades & 06 & 02 & 03 & 01 & 02 \\
\hline Tipo & & por gravidade & & & centrífuga \\
\hline Formato & retangular & circular & circular & circular & \\
\hline Diâmetro & & $25 \mathrm{~m}$ & $27 \mathrm{~m}$ & $27 \mathrm{~m}$ & \\
\hline Área total & $4.463 \mathrm{~m}^{2}$ & $981 \mathrm{~m}^{2}$ & $1.717 \mathrm{~m}^{2}$ & $572 \mathrm{~m}^{2}$ & \\
\hline Volume total & $15.619 \mathrm{~m}^{3}$ & $3.434 \mathrm{~m}^{3}$ & $24.900 \mathrm{~m}^{3}$ & $6.295 \mathrm{~m}^{3}$ & \\
\hline $\begin{array}{l}\text { Vazão de alimentação } \\
\text { por centrífuga }\end{array}$ & & & & & $36 \mathrm{~m}^{3} / \mathrm{h}$ \\
\hline
\end{tabular}


Tsutiya et al, 2001; Além Sobrinho, 2001, Andreoli et al, 2001; Chao, 2001; Silva, 2002; Metcalf \& Eddy, 2003; Dohanyos et al, 2004; Rulkens, 2004, Novak \& Park, 2004) estabelecendo relações e concentrações de sólidos em suspensão, eficiências de remoção e conceitos fundamentais no comportamento da fase sólida. As Tabelas 3, 4 e 5 apresentam valores típicos de projeto e faixas operacionais recomendadas para adensadores por gravidade, digestores anaeróbios e centrífugas (unidades integrantes da ETE Arrudas).

\section{METODOLOGIA}

Os dados utilizados no presente estudo foram disponibilizados pela COPASA. Esse material conta com os dados históricos do período de agosto de 2002 a junho de 2005. Todos os dados técnicos, informações operacionais e resultados das análises físico-químicas são catalogados, diariamente, em fichas. As análises são feitas no laboratório da ETE Arrudas.

\section{RESULTADOS E DISCUSSÃO}

\section{Concentrações de sólidos e relações entre variáveis}

A Tabela 6 apresenta os valores médios das concentraçōes de sólidos nas três fases de investigação do tratamento do lodo da ETE Arrudas, ao passo que a Tabela 7 resume as médias das variáveis operacionais do adensador por gravidade, digestor anaeróbio e desidratação por centrífuga. A interpretação dos resultados é feita separadamente, por etapa do tratamento, nos itens seguintes. As estatísticas descritivas completas estão apresentadas em Silva (2006).

\section{Avaliação do comportamento dos adensadores por gravidade}

A Figura 2 apresenta o box-plot (mediana, percentis 25\% e 75\% e valores máximos e mínimos) da taxa de aplicação de sólidos ao longo do sistema. Os valores médios da taxa de aplicação de sólidos para a primeira, segunda e terceira fases foram de $64 \mathrm{~kg} / \mathrm{m}^{2} . \mathrm{d}, 46 \mathrm{~kg} / \mathrm{m}^{2} . \mathrm{d}$ e $19 \mathrm{~kg} / \mathrm{m}^{2} . \mathrm{d}$, respectivamente. Conforme a Tabela 3 , esses valores encontram-se dentro dos valores reportados na literatura para lodos primários, secundários e mistos. Na Fase 3, em que o adensador recebia apenas lodo secundário, naturalmente as taxas de aplicação são menores.

O tempo de detenção hidráulica médio foi de 49 horas, 28 horas e 26 horas para as fases 1,2 e 3 , respectivamente, e estiveram sempre acima dos

Tabela 3 - Parâmetros de projeto de adensadores por gravidade

\begin{tabular}{|c|c|c|c|c|}
\hline \multirow[t]{2}{*}{ Tipo de Lodo } & \multicolumn{2}{|c|}{ Teor de sólidos (\%) } & \multicolumn{2}{|c|}{$\begin{array}{c}\text { Taxa de aplicação } \\
\left(\operatorname{kg~ST} / \mathrm{m}^{2} . \text { dia }\right)\end{array}$} \\
\hline & $\begin{array}{c}\text { Lodo } \\
\text { afluente }\end{array}$ & $\begin{array}{c}\text { Lodo } \\
\text { adensado }\end{array}$ & IWA/WEF & ABNT \\
\hline Lodo primário & $2,0-7,0$ & $5,0-10,0$ & $100-150$ & $<150$ \\
\hline Lodo ativado convencional & $0,5-1,5$ & $2,0-3,0$ & $20-40$ & $<30$ \\
\hline Lodo misto (primário + lodo ativado) & $0,5-1,5$ & $4,0-6,0$ & $24-70$ & $<50$ \\
\hline \multicolumn{2}{|c|}{ Fonte: Adaptado de Jordão; Pessoa, 2005, p. 295.} & \multicolumn{2}{|c|}{ Tabela 4 - Condições operacionais recomendadas para a digestão anaeróbia } & \\
\hline \multicolumn{2}{|l|}{ Principais parâmetros } & \multicolumn{3}{|c|}{ Valor recomendado } \\
\hline \multicolumn{2}{|l|}{ Tempo de digestão } & \multicolumn{3}{|c|}{20 a 25 dias } \\
\hline \multicolumn{2}{|l|}{ Temperatura média } & \multicolumn{3}{|c|}{25 a $30^{\circ} \mathrm{C}$} \\
\hline \multicolumn{2}{|l|}{ Carga orgânica volumétrica } & \multicolumn{3}{|c|}{$\leq 1,9 \mathrm{kgSTV} / \mathrm{m}^{3} \cdot \mathrm{d}$} \\
\hline $\mathrm{pH}$ & & \multicolumn{3}{|c|}{6,8 a 7,2} \\
\hline Acidez volátil & & \multicolumn{3}{|c|}{50 a $300 \mathrm{mg} / \mathrm{L}$} \\
\hline Alcalinidade total & & \multicolumn{3}{|c|}{1.000 a $3.000 \mathrm{mg} / \mathrm{L}$} \\
\hline Relação acidez/alcalinidade & & \multicolumn{3}{|c|}{0,05 a 0,1} \\
\hline STF/ST & & \multicolumn{3}{|c|}{40 a $60 \%$} \\
\hline \% metano no gás & & \multicolumn{3}{|c|}{ Acima de $65 \%$} \\
\hline \multicolumn{2}{|c|}{ Fonte: Adaptado de Silva,1982, p. 3; Luduvice, 2001, p. 135.} & \multicolumn{3}{|c|}{ STV = sólidos totais voláteis } \\
\hline \multicolumn{2}{|c|}{ Parâmetro } & \multicolumn{3}{|c|}{ Quantidade } \\
\hline \multicolumn{2}{|l|}{ Captura de sólidos } & \multicolumn{3}{|c|}{80 a $95 \%$} \\
\hline \multicolumn{2}{|c|}{ Concentração de sólidos na torta desidratada } & \multicolumn{3}{|c|}{20 a $30 \%$} \\
\hline \multicolumn{2}{|c|}{ Consumo de polímero para lodo misto digerido } & \multicolumn{3}{|c|}{4 a $6 \mathrm{~kg}$ de polímero por tonelada de ST } \\
\hline
\end{tabular}

Fonte: Adaptado de WEF, 1992, p. 1194; von Sperling, Gonçalves; Luduvice, 2001, p. 212. 
Silva, A. V. A.; von Sperling, M.; Oliveira Filho, J. M.

Tabela 6 - Concentrações médias de sólidos ao longo da fase sólida da ETE Arrudas

\begin{tabular}{ccccc}
\hline Local & Parâmetro & \multicolumn{3}{c}{ Concentração de sólidos (\%) } \\
& & Fase 1 & Fase 2 & Fase 3 \\
\hline Lodo primário & ST & 3,72 & 2,43 & 4,38 \\
Lodo secundário excedente & SST & & 0,70 & 0,59 \\
Lodo adensado & ST & 4,78 & 2,70 & 1,71 \\
& SV & 3,04 & 1,84 & 1,28 \\
Lodo digerido (dig. primário) & ST & 3,41 & 1,97 & 1,82 \\
& SV & 2,00 & 1,19 & 1,13 \\
Lodo desidratado & ST & 28,21 & 23,41 & 23,17 \\
\hline
\end{tabular}

Tabela 7 - Valores médios das variáveis operacionais das unidades componentes da fase sólida da ETE Arrudas

\begin{tabular}{|c|c|c|c|c|}
\hline \multirow[t]{2}{*}{ Unidade } & \multirow[t]{2}{*}{ Variável } & \multicolumn{3}{|c|}{ Período } \\
\hline & & Fase 1 & Fase 2 & Fase 3 \\
\hline \multirow{3}{*}{$\begin{array}{l}\text { Adensador por } \\
\text { gravidade }\end{array}$} & Tempo de detenção hidráulica (h) & 49 & 28 & 26 \\
\hline & Taxa de aplicação de sólidos $\left(\mathrm{kgST} / \mathrm{m}^{2} . \mathrm{d}\right)$ & 64 & 46 & 19 \\
\hline & Captura de sólidos (\%) & 18 & 21 & 66 \\
\hline \multirow{7}{*}{$\begin{array}{l}\text { Digestor } \\
\text { anaeróbio }\end{array}$} & Tempo de detenção hidráulica (d) & 35 & 47 & 22 \\
\hline & Carga orgânica volumétrica $\left(\mathrm{kgSV} / \mathrm{m}^{3} . \mathrm{d}\right)$ & 0,90 & 0,32 & 0,90 \\
\hline & \% de remoção de SV (\%) & 37 & 36 & 43 \\
\hline & Relação SV/ST & 0,58 & 0,61 & 0,62 \\
\hline & Relação acidez/alcalinidade & - & 0,07 & 0,07 \\
\hline & $\mathrm{pH}$ & 7,5 & 7,2 & 7,1 \\
\hline & Temperatura $\left({ }^{\circ} \mathrm{C}\right)$ & 27,6 & 26,6 & 26,4 \\
\hline \multirow[t]{5}{*}{$\begin{array}{l}\text { Desidratação } \\
\text { (centrífuga) }\end{array}$} & $\begin{array}{c}\text { Concentração de lodo afluente (\%) (dig. } \\
\text { secundário) }\end{array}$ & - & 3,06 & 2,56 \\
\hline & Captura de sólidos (\%) & - & 77 & 75 \\
\hline & $\begin{array}{c}\text { Concentração média de ST na torta } \\
\text { desidratada (\%) }\end{array}$ & 28,3 & 23,4 & 23,2 \\
\hline & Volume diário da torta (m³/dia) & 33 & 33 & 50 \\
\hline & Concentração de ST no líquido drenado (\%) & 0,57 & 0,88 & 0,69 \\
\hline
\end{tabular}

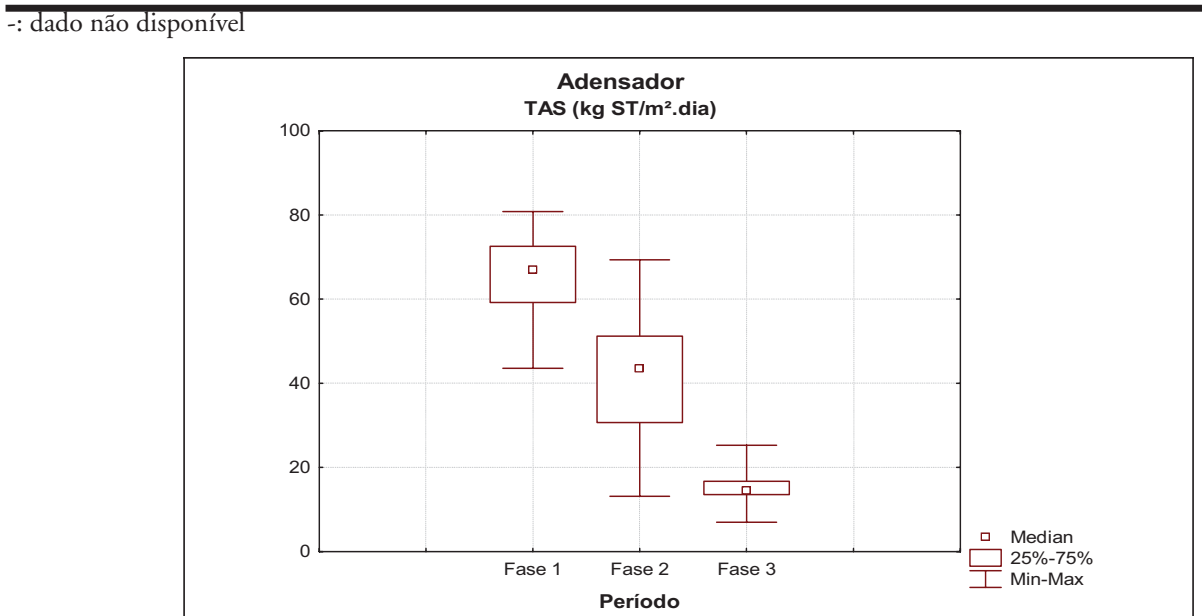

Figura 2 - Box-plot da taxa de aplicação de sólidos no adensador por gravidade 
valores reportados na literatura, que indicam valores máximos de 24 horas. Esses valores podem ser explicados pelo fato dos adensadores por gravidade terem sido projetados para receber lodo misto e terem operado na primeira fase somente com lodo primário e na terceira fase com lodo excedente secundário. Mesmo na segunda fase (condição de operação de projeto), houve altos tempos de detenção hidráulica, provavelmente, por não se ter uma retirada contínua do lodo dos decantadores primários, mas somente descargas de hora em hora com o movimento das pontes raspadoras de lodo e também por não ter sido atingida ainda a vazão de projeto.

A eficiência de captura de sólidos durante a primeira fase de operação apresentou uma média de 17,9\%. Esse valor encontra-se bem abaixo dos valores da literatura. Segundo Qasim (1985 apud von Sperling; Gonçalves, 2001), valores de captura de sólidos para o lodo primário adensado por gravidade encontram-se na faixa de 85 a $92 \%$. Uma das explicações investigadas é que a estação foi projetada para tratar o lodo misto adensado por gravidade e não apenas o primário. $\mathrm{O}$ tempo de detenção hidráulica nos adensadores, durante a primeira fase, foi de 49 horas, ou seja, bem elevado, causando decomposição do lodo e início de flotação no adensador. Isso ocasionou uma elevação na concentração de sólidos no líquido sobrenadante, reduzindo substancialmente o processo de captura de sólidos e interferindo na operação do decantador primário.

$\mathrm{Na}$ segunda fase de investigação, o adensador operou segundo a concepção do projeto (adensamento de lodo misto), mas com uma vazão afluente bem aquém da prevista em projeto. A média da captura foi de $21,1 \%$. Esse valor também se encontra abaixo dos valores reportados pela literatura, que indicam uma faixa de 80 a $90 \%$ de captura do lodo misto no processo de adensamento por gravidade.

O valor médio da captura de sólidos durante a terceira fase foi de $66,0 \%$. Segundo a literatura, valores satisfatórios da eficiência de captura de sólidos para lodo secundário adensado por gravidade variam de 75 a $85 \%$ (von Sperling; Gonçalves, 2001). Na ETE Arrudas, os resultados apresentaramse abaixo do esperado durante todas as fases de investigação. A melhoria da captura na terceira fase é evidente pelo gráfico. Nesse período, o tempo de detenção hidráulica nos adensadores foi de 26 horas, recebendo vazão constante de lodo excedente. Esse fato melhorou, sensivelmente, a captura de sólidos quando comparado com as duas fases anteriores. A Figura 3 apresenta conjuntamente as séries temporais da captura de sólidos e da taxa de aplicação de sólidos no adensador por gravidade. Verifica-se a inter-relação entre a TAS e captura de sólidos da seguinte forma: para uma menor taxa de aplicação tem-se uma maior captura de sólidos, e maiores taxas estão associadas a menores capturas.

\section{Avaliação do comportamento dos digestores}

$\mathrm{Na}$ primeira fase, com apenas um digestor em operação, a carga orgânica volumétrica média foi de $0,9 \mathrm{kgSTV} / \mathrm{m}^{3}$.d. $\mathrm{Na}$ segunda fase havia dois digestores em operação, e a carga média aplicada foi de $0,32 \mathrm{kgSTV} / \mathrm{m}^{3}$.d, inferior às taxas médias recomendadas pela literatura (em virtude da vazão de lodo ser ainda bem inferior à de projeto). $\mathrm{Na}$ terceira fase, a carga média de sólidos voláteis foi de $0,90 \mathrm{kgSTV} / \mathrm{m}^{3} . \mathrm{d}$, valor este satisfatório, conforme apontado na Tabela 4.

$\mathrm{Na}$ primeira fase estava funcionando apenas um digestor primário, $\mathrm{o}$ que resultou num tempo de detenção hidráulica de 35 dias (acima do usual), com temperatura média de $27,6^{\circ} \mathrm{C}$. O tratamento secundário ainda não estava em operação, existindo somente lodo primário adensado a ser bombeado para o digestor. A partir da segunda fase foi colocado um segundo digestor primário em operação, e o tempo de detenção hidráulica médio foi de 47 dias (Fase 2), com temperatura média de $26,6{ }^{\circ} \mathrm{C}$ e 22 dias para uma temperatura média de 26,4 ${ }^{\circ} \mathrm{C}$ (Fase 3). Nota-se que apenas a terceira fase apresentou um tempo de detenção hidráulica mais próximo ao valor de projeto (25 dias), embora a vazão média afluente à ETE estivesse abaixo da capacidade instalada. Quanto à temperatura do lodo, verifica-se uma compatibilidade com os tempos de detenção, os quais estiveram sempre acima de 21 dias.

A eficiência de remoção de STV usual na digestão anaeróbia situa-se entre 40 e 55\% (Silva, 1982; von Sperling; Gonçalves, 2001). A Figura 4 apresenta o Box-plot da eficiência de remoção de sólidos voláteis durante todas as três fases. As eficiências médias de remoção de STV foram de 37\%, 36\% e 43\%, nas fases 1,2 e 3, respectivamente.

A remoção de sólidos voláteis nos digestores anaeróbios está relacionada com a produção de biogás. A Tabela 8 mostra a produção unitária de biogás $\left(\mathrm{m}^{3}\right.$ por $\mathrm{kg}$ de STV afluente aos digestores e $\mathrm{m}^{3} / \mathrm{kgSTV}$ destruído). Os valores da ETE Arrudas estão próximos aos indicados pela literatura, que variam de 0,75 a $1,12 \mathrm{~m}^{3} / \mathrm{kgSTV}$ destruído (Metcalf \& Eddy, Inc., 2003; WEF, 1992). Observase pela Tabela 8 que a maior produção de biogás por kgSTV destruído aconteceu na primeira fase, quando o digestor recebia somente lodo primário adensado, com uma concentração de 4,78\%. Durante a segunda fase essa produção foi de 1,33 kgSTV/destruído. Na terceira fase houve a menor produção de biogás por kgSTV destruído, mas ainda dentro dos valores reportados pela literatura.

\section{Avaliação do comportamento da desidratação}

A média do volume de lodo desidratado da ETE Arrudas, durante a primeira fase, foi de $33 \mathrm{~m}^{3} / \mathrm{d}$. Na segunda fase, a produção média de lodo desidratado permaneceu em $33 \mathrm{~m}^{3} / \mathrm{d}$. Durante a terceira fase, houve um aumento do volume da torta desidratada, produzindo um volume médio de $50 \mathrm{~m}^{3} / \mathrm{d}$. Esse crescimento do volume de lodo desidratado nos meses de novembro de 2004 a janeiro de 2005 indicou a necessidade de um maior número de horas de operação das centrífugas.

A concentração do lodo desidratado teve seu maior valor (média de 28\%) na Fase 1, em que se tinha apenas lodo primário. Nas duas fases subseqüentes, em que se passou a ter o tratamento secundário completo, a concentração caiu para um valor médio de $23 \%$, mas ainda assim usual para centrífugas. Nas fases 2 e 3, a captura de sólidos na centrífuga foi também baixa (cerca de $75 \%)$.

\section{CONCLUSÕES}

De maneira geral, a Estação de Tratamento de Esgotos do Arrudas apresentou um desempenho e comportamento satisfatórios com relação à etapa do tratamento do lodo. Com 


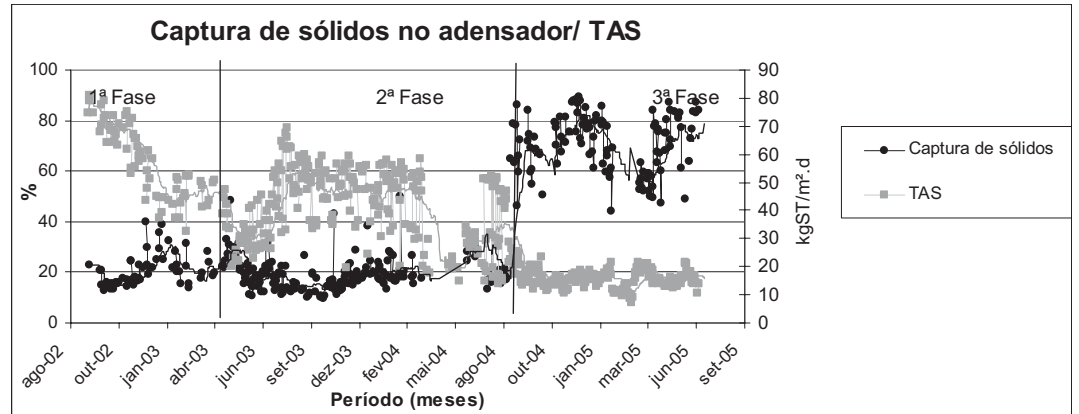

Figura 3 - Séries temporais da captura de sólidos e da taxa de aplicação de sólidos no adensador

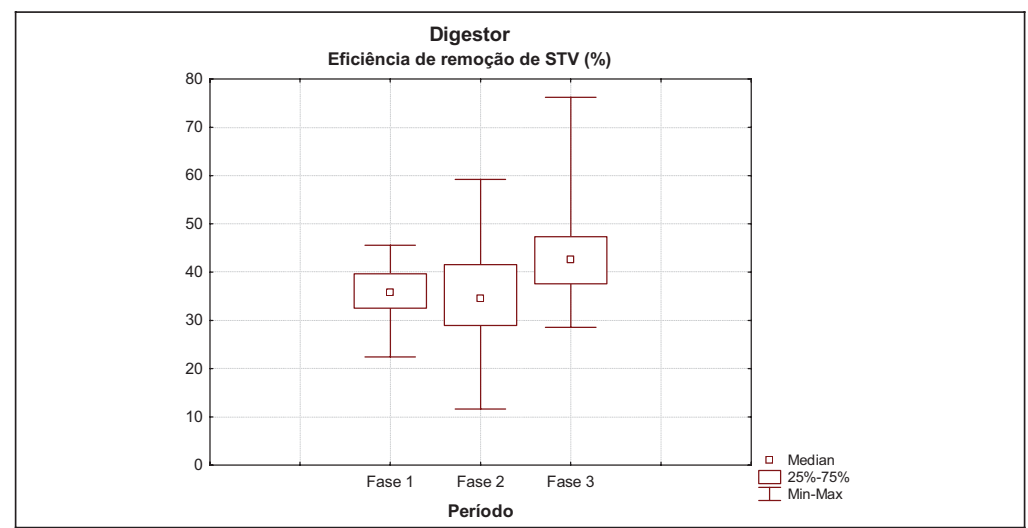

Figura 4 - Box-plot da eficiência da remoção de sólidos totais voláteis nos digestores

Tabela 8 - Produção unitária de biogás nas três fases

\begin{tabular}{ccc}
\hline Fases & $\begin{array}{c}\text { Produção de biogás }\left(\mathrm{m}^{3}\right) / \\
\mathrm{kgSTV} \text { afluente aos digestores } \\
\left(\mathrm{m}^{3} / \mathrm{kgSTV}\right)\end{array}$ & $\begin{array}{c}\text { Produção de biogás/ } \\
\mathrm{kgSTV} \text { destruído } \\
\left(\mathrm{m}^{3} / \mathrm{kgSTV}\right)\end{array}$ \\
\hline 1 & 0,74 & 1,58 \\
2 & 0,55 & 1,33 \\
3 & 0,35 & 0,91 \\
\hline
\end{tabular}

base na análise dos dados históricos disponíveis dos anos de 2002 a 2005 e do cálculo das principais relaçôes e taxas de aplicação foi possível extrair as seguintes conclusóes:

- A maior concentração de lodo primário se deu quando o mesmo foi adensado nos próprios decantadores primários, ou seja, durante a terceira fase;

- Devido às variações de processo nas três fases, houve um decréscimo nas concentraçôes do lodo nos adensadores por gravidade: Fase 1 (somente lodo primário): 4,8\%; Fase 2 (lodo misto): 2,7\%; Fase 3 (somente lodo secundário): $1,7 \%$.

- As concentrações de sólidos totais no lodo digerido decresceram da primeira fase para a terceira fase: Fase 1 (somente lodo primário): 3,4\%; Fase
2 (lodo misto): 2,0\%; Fase 3 (lodo misto): $1,8 \%$.

- A maior concentração de sólidos no lodo desidratado por centrifugação ocorreu na primeira fase, quando o lodo digerido era somente de origem primária. Nas segunda e terceira fases houve a ocorrência de concentrações semelhantes do lodo desidratado originário do lodo misto digerido: Fase 1: 28,2\%; Fase 2: 23,4\%; Fase 3: 23,3 \%.

- Nas três fases de operação observou-se que a produção de biogás por kg de sólidos totais voláteis esteve entre 0,9 a 1,6 m3 de gás por kgSTV destruído;

- O adensamento por gravidade, projetado para lodo misto, não conseguiu conduzir às concentraçôes esperadas.

\section{REFERÊNCIAS}

ALÉM SOBRINHO, P. Tratamento de esgoto e geração de lodo. In: TSUTIYA, M. T. Biossólidos na agricultura. São Paulo: SABESP, cap. 3, p. 41-87. cap. 2, p. 7-40. 2001 .

ANDREOLI, C. V.; VON SPERLING, M.; FERNANDES, F. (Org.). Lodo de esgotos: tratamento e disposição final. Belo Horizonte: Departamento de Engenharia Sanitária e Ambiental, UFMG; Curitiba: SANEPAR, 484 p. (Princípios do tratamento biológico de águas residuárias, v. 6). 2001

CHAO, I. R. S. Diagnóstico e otimizacãa dos adensadores por gravidade. In: $21^{\circ}$ CONGRESSO BRASILEIRO DE ENGENHARIA SANITÁRIA E AMBIENTAL, Joinville. Anais eletrônico... ABES, p. 1-6. 2001 .

DOHÁNYOS, M. et al. Improvement of anaerobic digestion of sludge. Water Science \& Technology, v. 49, n. 10, p. 89-96, 2004.

JORDĀO, E. P.; PESSOA, C. A. Tratamento de esgotos domésticos. 4. ed. Rio de Janeiro: ABES, 932 p. 2005.

LUDUVICE, M. Processos de estabilização de lodos. In: ANDREOLI, C. V.; VON SPERLING, M.; FERNANDES, F. (Org.). Lodo de esgotos: tratamento e disposição final. Belo Horizonte: Departamento de Engenharia Sanitária e Ambiental, UFMG; Curitiba: SANEPAR, 484 p. (Princípios do tratamento biológico de águas residuárias, v. 6). cap. 4, p. 123-157. 2001.

METCALF \& EDDY, INC. Wastewater engineering treatment, disposal and reuse. 4th ed. Boston: McGraw-Hill, 1819 p. (McGraw-Hill series in civil and environmental engineering). c2003.

NOVAK, J. T.; PARK, C. Chemical conditioning of sludge. Water Science \& Technology, v. 49, n. 10 , p. $73-80,2004$

RULKENS, W. H. Sustainable sludge management: what are the challenges for the future? Water Science \& Technology, v. 49, n. 10, p. $11-19,2004$

SILVA, A .V. A. Avaliação do tratamento do lodo da ETE Arrudas- MG (Lodos ativados convencional). 108 p. Dissertação (Mestrado em Saneamento, Meio Ambiente e Recursos Hídricos)- Escola de Engenharia, Universidade Federal de Minas Gerais, Belo Horizonte. 2006.

SILVA, M. O. S. A. Manual de operação da ETE Arrudas. Belo Horizonte: Companhia de Saneamento de Minas Gerais - COPASA, 7 v. 2002.

SILVA, M. O. S. A. Tratamento de lodos de esgotos por digestão anaeróbia. In: $1^{\circ}$ SIMPÓSIO LATINO AMERICANO SOBRE A PRODUCCÃO DE BIOGÁS A PARTIR DE RESÍDUOS ỎRGÂNICOS, Anais... São Paulo: SABESP, [1982]. p. 1-34. 1982.

TSUTIYA, M. T. Biossólidos na agricultura. São Paulo: SABESP, cap. 3, p. 41-87. 2001 a.

VON SPERLING, M. Lodos ativados. Belo Horizonte: Departamento de Engenharia Sanitária e Ambiental, UFMG, (Princípios do tratamento biológico de águas residuárias, 4). 416 p. 1997.

VON SPERLING, M.; GONÇALVES, R. F. Lodo de esgotos: características e produçāo. In: ANDREOLI, C. V.; VON SPERLING, M.; 
FERNANDES, F. (Org.) Lodo de esgotos: tratamento e disposição final. Belo Horizonte: Departamento de Engenharia Sanitária e Ambiental, UFMG; Curitiba: SANEPAR, 484 p. (Princípios do tratamento biológico de águas residuárias, v. 6). cap. 2, p. 17-67. 2001.

VON SPERLING, M.; GONÇALVES, R. F.; LUDUVICE, M. Remoção da umidade de lodos de esgotos. In: ANDREOLI, C. V.; VON SPERLING, M.; FERNANDES, F. (Org.) Lodo de esgotos: tratamento e disposição final. Belo Horizonte: Departamento de Engenharia Sanitária e Ambiental, UFMG; Curitiba: SANEPAR, 484 p. (Princípios do tratamento biológico de águas residuárias, v. 6). cap. 5, p. 159-259. 2001.

WATER ENVIRONMENT FEDERATION - WEF. Design of municipal wastewater treatment plants. Alexandria, VA: Water Environment Federation; New York, NY: American Society of Civil Engineers, (WEF manual of practice, n. 8). (ASCE manual and report on engineering practice, n. 76). 1992

\section{Endereço para correspondência:}

\section{Marcos von Sperling}

Departamento de Engenharia Sanitária e Ambiental da UFMG.

Av. Contorno 842 - $7^{\circ}$ andar

30 I l 0-060 Belo Horizonte - MG

\section{- Brasil}

Tel: (3 I) 3238-1935

Fax: (3I) 3238-I879

E-mail: marcos@desa.com.br 